Kadushin. A. (1978). Children in foster families and institutions. In H.S. Maas (Ed.). Sorial service research: Revieu's of studies, (pp. 90-148). Washingon DC: National Association of Social Workers.

Lahti, J., Green, K., Emlen, A., Zadny, J., Clarkson, Q.D.. Kuehnel, M.. \& Casciato. J. (1978). A follou-up study of the Oregon Project. Portland. OR: Portland State Lniversity. Regional Research Institute for Human Services.

Stein. T.J., Gambrill, E.D., \& Wiltse. K.T. (1978). Children in foster homes: Achiening comtinuity of care. New York: Praeger Special Studies.

Wiltse. K.T. (1978). Current issues and new directions in foster care. In Child Welfare strateg: in the coming vears (DHEW OHDS No. 78-30158) (pp. 51-89). Washington. DC: Department of Health, Education and Welfare. Children's Bureau.

\title{
Child Welfare: Current Dilemmas, Future Directions
}

Edited by Brenda G. McGowan and William Meezan

Itasca, IL: F.E. Peacock Publishers, 1983, $519+$ xiv pp., $\$ 21.95$ (hardcover).

This book offers a blueprint for implementing permanency planning for children in nearly all child welfare programs in the 1980s. Noting that child welfare services are criticized severely for failing to fulfill an increasingly wide range of functions, editors Brenda McGowan and William Meezan propose that realistic expectations for child welfare agencies be delineated and that mechanisms to insure that agencies can fulfill their primary functions be developed. The contributions from 14 child welfare authorities attempt to recapture a view of child welfare services as a residual svstem.

The three chapters in Part I describe current problems in child welfare and provide an analysis of service delivery and of policy decisions that led to the development of these problems. In the opening chapter. Meezan offers seven principles that are necessary for implementing permanency planning. This chapter is a concise, well organized introduction to the concept of permanency planning and to the major points amplified in subsequent chapters. The remaining two chapters provide brief overviews of the historical evolution of child welfare services and of major federal and state laws, court decisions, and administrative directives shaping child welfare policy. Allen and kinitzer have written an interesting inventory of the components of child welfare policies and succinct descriptions of recent, important policy modifications. This first section provides a good, brisk review of the development of problems in the child welfare field.

Part II focuses on policy and program initiatives aimed at enhancing the functioning of all families, as well as special services for families and children at risk of separation from each other. Demonstrating some of the uneveness that seems inevitable with edited works, Kamerman and Kahn's chapter provides a provocative outline of a "child and family policy 
agenda," but moves too quickly for readers unfamiliar with certain income maintenance programs and personal social services not available in this country. Carmine Magazino makes a thoughtful presentation of issues and programs involved in the shifts in emphasis from substitute care to supplementary and supportive care for families and children at risk of separation. Program descriptions and case examples enrich the discussion of services for this population.

The essential message of the six chapters in Part III is that substitute care should be viewed as temporary and, more importantly, as a vehicle for permanency planning. Toward this end, Stein and Rzepnicki offer a thorough analysis of decision-making in protective services, foster care, and adoption, bolstering their statements with research and posing a strong argument for the importance of decision-making as a vehicle for achieving permanence for children. Over the years, stable, continuous living arrangements have been especially elusive for foster children, with all too many experiencing so-called foster care "drift." Blumenthal's excellent chapter describing the critical concepts of foster care and highly specific suggestions for working with biological parents, children, and foster parents suggests that foster care services can be effective. Remaining chapters in this section discuss services for special populations of children, achieving permanence for children in the substitute care system, adoption of special needs children, and personnel issues in child welfare.

The varying levels of sophistication across chapters was a minor annoyance for this reader. More disconcerting was the inadequate empirical support, particularly related to service effectiveness, which cropped up in a few chapters. At a minimum, the need for careful evaluation of more recent and proposed service innovations should be strongly stated. By and large, however, the contributors to this book display an intimate knowledge of the policies and programs they review. Major issues confronting the child welfare system are clearly set forth and thoroughly assessed. The volume stands as an exemplar of policy and program analysis as well as an important piece on child welfare. Professionals in the child welfare field will do well to study it.

\author{
Betty J. Blythe \\ University of Michigan
}

Foster Children in the Courts

Edited by Mark Hardin

Boston: Butterworth Legal Publishers, 1983, 653 pp. $\$ 45.00$.

The recent trend toward increased judicial monitoring of foster care services makes this an important and timely publication. The very title of this 